\title{
A Molecularly Imprinted Electrochemical Sensor Based on Polypyrrole/Carbon Nanotubes Composite for the Detection of S-ovalbumin in Egg White
}

\author{
Qi Zeng, Xi Huang, Meihu Ma*
}

National Research and Development Center for Egg Processing, College of Food Science and Technology, Huazhong Agricultural University, Wuhan, Hubei 430070, PR China.

*E-mail: mameihuhn@163.com

doi: $10.20964 / 2017.05 .61$

Received: 23 February 2017 / Accepted: 19 March 2017 / Published: 12 April 2017

\begin{abstract}
A rapid and accurate detection of S-ovalbumin is essential for determining the freshness and quality of avian egg due to the significant correlation between them. An electrochemical sensor for S-ovalbumin detection was fabricated based on molecularly imprinted polymer (MIP) on the glass carbon electrode modified with multi-walled carbon nanotubes (MWCNTs) and chitosan (CS). The modified materials were characterized by infrared spectrometry and scanning electron microscopy. The performance of the modified electrodes, the relation between response current and analyte concentrations as well as the selectivity and practicability of MIP sensor were systematically evaluated by cyclic voltammetry, differential pulse voltammetry and electrochemical impedance spectroscopy. Under the optimum operating conditions, the fabricated electrochemical sensor showed a linear current response to the target concentration in the range from $10^{-8}$ to $10^{-4} \mathrm{mg} / \mathrm{mL}$ with a detection limit of $2.95 \times 10^{-9} \mathrm{mg} / \mathrm{mL}$ in S-ovalbumin detection. Additionally, the proposed sensor exhibited good selectivity, high sensitivity and desirable stability.
\end{abstract}

Keywords: Molecularly imprinted polymer; polypyrrole; electrochemical sensor; S-ovalbumin; egg white

\section{$\underline{\text { FULL TEXT }}$}

(C) 2017 The Authors. Published by ESG (www.electrochemsci.org). This article is an open access article distributed under the terms and conditions of the Creative Commons Attribution license (http://creativecommons.org/licenses/by/4.0/). 